DOI 10.37882/2500-3682.2020.12.38

\title{
КИТАЙСКАЯ КУЛЬТУРНО-ЦИВИЛИЗАЦИОННАЯ ИДЕНТИЧНОСТЬ В СОВРЕМЕННУЮ ЭПОХУ
}

\section{CHINESE CULTURAL AND CIVILIZATIONAL IDENTITY IN CONTEMPORARY TIMES \\ Cui Jiawen}

Summary: The article is devoted to a comprehensive study of the Chinese cultural and civilizational identity in contemporary times. According to the author, the core of the Chinese cultural and civilizational identity is the traditional Chinese culture, which includes ethics and morality, political thoughts, traditions and customs of the Chinese people. Nowadays in China, there has been a strong interest in traditional culture and its spiritual pillars. The author analyzes the Chinese dream of the rejuvenation of the Chinese nation, the concept of A community with shared future for mankind, and also clarifies the core socialist values.

Keywords: identity, Confucianism, Taoism, values, political thoughts, core socialist values, the concept of A community with shared future for mankind
B условиях глобализации в последние годы большое внимание уделено проблематике культурно-цивилизационной идентичности в Китае и России. Ученые исследуют данную проблематику с разных точек зрения.

Китайские ученые Чжун Синсин, Цзо Бинь и Вэнь Фанфан согласны в том, что культурная идентичность включает в себя общее понимание людьми природных и социальных явлений. Они считают, что можно разделить культурную идентичность на три уровня: первый - слой выражения культурной идентичности, то есть идентичность/принятие форм культуры; второй - это защитный слой культурной идентичности, то есть идентичность/ принятие культурных норм, которые люди соблюдают в общении и создают разные социальные сообщества; третий - ядровый слой культурной идентичности, то есть идентификация культурных ценностей, которые урегулируют поведение людей, определяют идеалы, эстетические взгляды и т.д. [1, С.175-187]

Чжун Синсин считает, что под культурной идентичностью понимается признание, принятие и сознательная практика людьми определенной культуры, а также формирование собственной идеологической системы в соответствии с культурой для самоидентификации, интеграции в сходные группы.

В систему китайской культурно-цивилизационной

\author{
Цуй Цзявэнь \\ Аспирант, Российская академия народного хозяйства и \\ государственной службы при Президенте РФ \\ tszyaven.tsuy@mail.ru
}

Аннотация: Статья посвящена комплексному исследованию китайской культурно-цивилизационной идентичности в современную эпоху. По мнению автора, ядром китайской культурно-цивилизационной идентичности является традиционная китайская культура, в которую входят этика и нравственность, политические мысли, традиции и обычаи китайского народа. В современных условиях в Китае в высшей степени актуализирован интерес к традиционной китайской культуре, к ее духовной матрице. В статье проанализированы концепция китайской мечты о великом возрождении китайской нации, концепция сообщества единой судьбы человечества, а также выяснены стержневые социалистические ценности.

Ключевые слова: идентичность, конфуцианство, даосизм, ценности, политические мысли, стержневые социалистические ценности, концепция сообщества единой судьбы человечества.

идентичности входят традиционная китайская культура и отражение ее в таких современных главенствующих ценностях в китайском обществе, как стержневые социалистические ценности, концепция китайской мечты о великом возрождении китайской нации и концепция сообщества единой судьбы человечества.

По содержанию традиционная китайская культура состоит из трех частей - этики и нравственности, политических мыслей, традиций и обычаев китайского народа.

Китайская конфуцианская этика является стержнем китайской этики и культуры, а “仁" «жэнь/ добродетель/ гуманность/ человеколюбие/ милосердие» называется стержнем конфуцианской этики. Это основной принцип китайского морального мышления и основа для совершенствования человеческой и социальной морали. Конфуцианскую этику можно разделить на семейную, социальную и национальную. Семейная этика означает соблюдение сыновней почтительности к родителям, доброты по отношению к отцу и сыну, уважения к братьям и друзьям для формирования сильной семейной привязанности и поддержании гармонии в семье. Социальная этика расширяет сыновнюю почтительность до «веры, справедности, долга, правил, доброты, уважения, знания, гармонии», которая распространяется от семейной этики на общество и становится социальной этикой. Конфуцианство рассматривает самосовершенствование и работу над собой как основу жизни человека в мире 
и реализации человеческих ценностей. Национальная этика означает повышение семейной этики до уровня национальной. Управление страной похоже на управление семьей. Подданные должны быть верны по отношению к стране, а монарх должен быть добр к подданным.

Традиционная китайская мораль - это нравственная система, в которой доминирует конфуцианская этика. Она включает в себя моральные идеалы, нравственные нормы и моральное самосовершенствование человека. Многие исследователи отмечали, что конфуцианская мораль характерна идеализмом, гуманизмом и рационализмом. Конфуцианская мораль идеалистична, она стремляется к самосовершенствованию и пытается формировать идеальную личность через совершенствование морали. Конфуцианство придает большое значение личности и придерживается принципа «гуманные любят других». Конфуцианство подчеркивает личную социальную ответственность, выдвигает «Добиваться самосовершенствования, в порядке содержать семью, управлять государством и нести Поднебесной мир», «Раньше всех горевать над горем Поднебесной и после всех наслаждаться её радостями». Конфуцианство выступает за коллективизм и требует, чтобы люди подчинялись и служили семье, обществу и стране. Конфуцианство придает большое значение нравственности личности и выступает за «доброжелательность и гуманизм». Конфуцианство выступает за то, чтобы «увидел мудреца и захотел стать таким же; следовать хорошим образцам» и «размышлять о своих недостатках, видя плохое», и требует, чтобы люди «постоянно проверяли себя и узнали свои недостатки». Конфуцианство обращает внимание на внутреннее совершенствование личности для достижения нравственного совершенства, а также изменяет и совершенствует себя, укрепляя личное моральное совершенствование.

Вторая составляющая часть китайской традиционной культуры - политические мысли разных философских школ, таких как конфуцианство, даосизм, легизм, моизм и Инь Ян Цзя. Мысль Конфуция берет за основу “仁"«жэнь/ добродетель/ гуманность/ человеколюбие/ милосердие» - любовь к другим. Он выдвинул принцип «не делай другим того, чего себе не желаешь», и выступал за принцип «верность и прощение» и продвигал «гуманность и человеколюбие» для управления страной. Мэнцзы унаследовал принципы Конфуция и развил их в теорию «гуманное правление», «народ - основа страны», и «те, кто управляет страной, нравственной добродетелью и этикетом, выигрывают мир, а те, кто не соблюдает принцип «гуманное правление», теряют весь мир». Конфуций подчеркивал «осуществлять управление страной добротой»: «Когда управляют страной с помощью политикой и наказанием, люди свободны от наказания, но остаются бесстыдными; а когда управляют страной с помощью морали и ограничивают народа этикетом - люди не только остаются вежливыми, но и умеют исправлять свои ошибки». Мэнцзы развивал мышление Конфуция и выдвинул, что «только с помощью доброты недостаточно для управления страной, и закон сам по себе не вступает в силу», что подчеркивает сочетание гуманизма и закона в правлении страной. Короче говоря, осуществление «гуманного правления» требует от правителя доброты по отношению к людям, и не чрезмерной эксплуатации и угнетения людей. В то же время требует, чтобы чиновники на всех уровнях думали о народе и работали на благо народа. Следовательно, управлять страной с помощью добродетели - значит обучать людей личным моральным качеством правителя, чтобы народ подчинялся правлению и соответственно установили полный порядок в Поднебесной, т.е. в стране царит мир и согласие.

Даосское «правление страной недеянием» отличается от активной политической идеологии и культуры конфуцианства. Так называемое «недеяние» - это не означает бездействие, а действие человечества по законам небес и природы, чтобы люди не чрезвычайно вмешивались в развитие природы, и дела развивались по естественным законам, только на этой основе осуществляется гармония и единение. Следовательно, «недеяние» является предпосылкой и условием для всех действий. Идеальное общество, к которому стремлялся Лао-цзы, это «маленькое государство с небольшим населением». Лао-цзы исходную идею политической власти видел в сверхъестественном дао, направляющим жизнь людей согласно естественным законам, избавляющим их от тиранического господства аристократии. Лао-цзы характеризует дао как независимый от небесного владыки естественный ход вещей, естественную закономерность. Дао определяет законы неба, природы и общества. Оно олицетворяет высшую добродетель и естественную справедливость. В отношении к дао все равны.

Легизм - одно из шести направлений философских школ Древнего Китая. Легисты рассмотрели закон как основный инструмент для правления страной, установления порядка о обществе и сохранения стабильности в стране. В философии Мо-цзы иную интерпретацию получили различные философские концепции. Центральным в учении моистов является принцип «всеобщей любви», который представляет собой этическое обоснование идеи равенства людей и требования свободных низов древнекитайского общества права участия в политической жизни. Представители философской школы Инь ян цзя рассматривают развитие социально-исторического процесса и смену династий как закон взаимного ограничения пяти элементов.

В современную эпоху стержневые социалистические ценности играют главную роль в китайской культурноцивилизационной идентичности. Стержневые социалистические ценности состоят из ценностей, которые от- 
носятся к трем группам идентичностей: во-первых, это государственная идентичность - богатство, могущество, демократия, цивилизация и гармония; во-вторых, это общественная идентичность - свобода, равенство, справедливость и законность; в-третьих, это гражданская идентичность - патриотизм, преданность своей работе, честность и дружелюбие. По мнению Си Цзиньпина, стержневые социалистические ценности «в полной степени воплощают в себе продолжение и сублимирование лучшей традиционной китайской культуры» [2, С. 235]

По мнению высшего руководства Китая, предпосылкой уверенности в культуре является культурная идентичность: только признавая ценность своей собственной культуры, можно обрести уверенность в собственной культуре и применить ее на практике. Благодаря культурной идентичности люди живут в культурном сообществе, имеют те же культурные ценности и культурные идеи. [3, С.29-32] Для укрепления китайской культурно-цивилизационной идентичности в ноябре
2012 года Си Цзиньпин выдвинул концепцию китайской мечты - великого возрождения китайской нации. Китайская мечта включает в себя три цели - создание процветающего и могущественного государства, осуществление национального возрождения и достижение народного благоденствия. Кроме этого, в 2012 году Китай выдвинул концепцию создания «сообщества единой судьбы человечества», которая основывается на ценностях и духовных критериях, созданных человечеством в процессе социальной эволюции. Концепция сообщества единой судьбы человечества тесно связана с китайской идеей «Поднебесной» и с традиционными понятиями гармонии. В концепции «Поднебесной» накоплены конфуцианские идеалы великого единения всего мира.

Традиционная китайская культура, стержневые социалистические ценности, концепции китайской мечты и сообщества единой судьбы человечества составляют китайскую культурно-цивилизационную идентичность В современную эпоху.

\section{ЛИТЕРАТУРА}

1. Чжун Синсин. Исследование культурной идентичности в современную эпоху. Кандитатская диссертация Партийной школы ЦК КПК. 2014. Цзо Бинь, Вэнь Фанфан. Культурная идентичность современных китайцев.// Вестник РАН Китая. 2017. С 175-187.

2. Чжао Инсюань. Распространение традиционной китайской культуры, укрепление уверенности в собственной культуре. // Сборник статей науки и образования. 2020(481). ( 29-32.

3. Си Цзиньпин о государственном управлении (2015) Пекин: Издательство литературы на иностранных языках. С. 235.

4. Выступление Си Цзиньпина на симпозиуме по философии и социологии. 习近平在哲学社会科学工作座谈会上的讲话（2016年5月17 日 ) http://cpc.people.com.cn/n1/2016/0519/c64094-28361550.html 